\title{
ESTUDOS E AÇÕES EM INFORMAÇÃO E EDUCAÇÃO - 2010
}

\author{
STUDIES AND ACTIONS IN INFORMATION AND EDUCATION - 2010
}

Relatório final do III Seminário Estudos e Ações em Informação e Educação.

Florianópolis, 06, 07 e 13 de dezembro de 2010.

\author{
Danielly Oliveira Inomata \\ Mestranda em Ciência da Informação - UFSC \\ inomata.danielly@gmail.com \\ Francisco das Chagas de Souza \\ Professor do Departamento de Ciência da Informação - UFSC \\ chagas@cin.ufsc.br \\ Gregorio Jean Varvakis Rados \\ Professor do Departamento de Ciência da Informação - UFSC \\ grego@deps.ufsc.br \\ Katiusa Stumpf \\ Mestranda em Ciência da Informação - UFSC \\ belabruxinha.13@gmail.com \\ Ketry Gorete Farias dos Passos \\ Mestranda em Ciência da Informação - UFSC \\ ketry2003@gmail.com \\ Sirlene Pintro \\ Mestranda em Ciência da Informação - UFSC \\ sirlene23@gmail.com
}

\section{INTRODUÇÃO}

Este texto expõe as atividades e discussões realizadas nos dias 06, 07 e 13 de dezembro de 2010, por ocasião da realização do III Seminário Estudos e Ações em Informação e Educação. Este evento, que já está em sua terceira edição, foi concebido para atender a dois propósitos fundamentais: 1 socializar a produção do conhecimento desenvolvido e em desenvolvimento no Grupo de Pesquisa Informação, Tecnologia e Sociedade - GRITS; 2 - atrair o interesse de outros estudantes, potenciais pesquisadores nas temáticas exploradas pelos membros do Grupo. Assim, esta comunicação visa a traduzir o sentido que se dá ao evento, ou seja, patentear as atividades de pesquisa e atuação para a 
sociedade, que são cumpridas no Grupo, sob a coordenação e/ou orientação de pesquisadores, docentes e estudantes de Mestrado e de Graduação nele integrados.

O evento foi promovido e realizado pelo GRITS, juntamente com o Programa de Pós-Graduação em Ciência da Informação - PGCIN/UFSC. Sua programação foi realizada no auditório Valpi Costa do Centro de Ciências da Educação (CED/UFSC) e teve como público alvo os estudantes de graduação e pós-graduação em Biblioteconomia, Arquivologia, Ciência da Informação, Pedagogia, além da comunidade externa. Os trabalhos apresentados para debate trataram da produção de pesquisa realizada e em desenvolvimento no grupo, no período de 2007 a 2010, dentro das abordagens que compõem as suas duas linhas temáticas. Um objetivo complementar que se pretende atingir com este texto é difundir o perfil e a atuação do GRITS, sua dinâmica de trabalho e os temas que desenvolveu no período em questão. Isso poderá ser conhecido, em parte, através dos tópicos a seguir.

\section{GRUPO DE PESQUISA: INFORMAÇÃO, TECNOLOGIA E SOCIEDADE - GRITS}

O Grupo de Pesquisa Informação, Tecnologia e Sociedade (GRITS) existe desde 1996, sediado no Departamento de Ciência da Informação da UFSC. Atualmente conta com a liderança dos professores Francisco das Chagas de Souza e Gregório Jean Varvakis Rados.

Informações sobre atividades do grupo estão disponíveis na página do Núcleo de Informação, Pesquisas e Estudos em Educação e Educação Bibliotecária - NIPEEB (http://nipeeb.blogspot.com). Para conhecer o Grupo de Pesquisa Informação, Tecnologia e Sociedade - GRITS e a produção e orientação de pesquisas nele realizadas, pode ser acessada a homepage do Diretório de Grupos do CNPq (http://dgp.cnpq.br/buscaoperacional/detalhegrupo.jsp?grupo=0043607JCBUJDZ).

O GRITS conta com duas linhas de pesquisa:

a) Gestão da Informação, qualidade e tecnologia - com o objetivo de desenvolver investigações na área de sistemas produtivos e suas bases informacionais, com ênfase especial na gestão da informação.

Esta linha conta com a participação de dois pesquisadores: Gleisy Regina Bóries Fachin e Gregório Jean Varvakis Rados, além de sete estudantes: Danielly Oliveira Inomata; Jacqueline Alexandre Martins; Katia Regina Starck; Ketry Gorete Farias dos Passos; Sirlene Pintro; Sulamita Maria Souza Morini; Tassiane Luckemeyer Altíssimo.

b) Informação, comunicação, educação e sociedade - com o objetivo de estudar os processos de comunicação imbricados na formação de profissionais das ciências da informação, comunicação e educação, levando em conta as características do ensino superior brasileiro e as infraestruturas e meios 
de comunicação da informação construídos e utilizados pela sociedade com objetivos formativos e informativos.

Esta linha conta com quatro pesquisadores: Elizete Vieira Vitorino; Francisco das Chagas de Souza; Renée Rosanne Vaz Nina e Valquíria Michela John, bem como o envolvimento de oito estudantes: Ana Claudia Perpétuo de Oliveira da Silva; Camila Zélia da Silva; Daniela Garcia; Daniella Câmara Pizarro; Gyance Carpes; Katiusa Stumpf; Maria Raimunda de Lira Cabral e Rafaela Paula Freitas.

Com o trabalho do Grupo, constituiu-se o Núcleo de Informação, Pesquisas e Estudos em Educação e Educação Bibliotecária, da UFSC. Em 1996, deu-se a criação, por membros do grupo, do periódico eletrônico "ENCONTROS BIBLI: Revista Eletrônica de Biblioteconomia e Ciência da Informação". Em seguida, foi criado o Laboratório de Gestão, Tecnologia e Informação (http://www.lgti.ufsc.br/index.htm). Mais adiante, implantou-se a biblioteca eletrônica: Educação Bibliotecária (http://www.ced.ufsc.br/bibliote/dep/saleitura.html), cujo conteúdo hoje está incorporado ao blog do NIPEEB, com acesso em: http://nipeeb.blogspot.com. Outra ação dirigiu-se à criação do Curso de Mestrado do Programa de Pós-Graduação em Ciência da Informação (PGCIN) da UFSC. Este Curso teve seu início em 11 de junho de 2003 e na avaliação trienal 2007-2009 da Coordenação de Aperfeiçoamento de Pessoal de Nível Superior - CAPES obteve o conceito 4.

O GRITS tem a interdisciplinaridade como elemento de política do grupo. Nele participam docentes, pesquisadores e estudantes oriundos do Programa de Pós-Graduação em Ciência da Informação e do Programa de Pós-Graduação em Gestão do Conhecimento. Em dezembro de 2004 e em dezembro de 2006 ${ }^{1}$, no campus da UFSC, em Florianópolis, o Grupo promoveu, respectivamente, seu primeiro e segundo Seminários com a finalidade de abrir à discussão a produção que realizou durante os anos 2003-2004 e 2005-2006. Nos últimos anos, vem se adensando a produção bibliográfica e técnica dos membros do grupo que promove, em dezembro de 2010, o terceiro Seminário, apresentando parte de sua produção referente ao período de 2007 a 2010.

\section{TRABALHOS APRESENTADOS NO III SEMINÁRIO ESTUDOS E AÇÕES EM INFORMAÇÃO E EDUCAÇÃO}

No primeiro dia do seminário (06/12/2010, $2^{\mathrm{a}}$ feira), o líder do grupo, professor Francisco das Chagas de Souza, fez um breve discurso de abertura, cumprimentando a todos os presentes e apresentando as

\footnotetext{
${ }^{1}$ Informações sobre o evento, edições de 2004 e 2006, estão disponíveis respectivamente em: http://www.periodicos.ufsc.br/index.php/eb/article/view/101/5503 ; http://www.periodicos.ufsc.br/index.php/eb/article/download/432/417 
linhas de pesquisa e os integrantes do GRITS. Fez um sucinto resgate histórico do Grupo e das conquistas alcançadas pelo mesmo. Versou sobre a relevância da participação dos profissionais, cujas práticas e ideias podem ser transformadas em conhecimento. Expôs que o Grupo necessita de visibilidade para articular parcerias com outros grupos de pesquisa e, nesse processo, promover intercâmbio entre professores, de maneira a receber professores visitantes para discutir metodologias, teorias, ferramentas, etc., visando trocar experiências, ao mesmo tempo em que ensinam e aprendem. Em sua fala introdutória, evidenciou que o grupo é consolidado com a Ciência da Informação, mas mantém laços laterais com outros programas, aos quais os professores estão vinculados, como a Gestão do Conhecimento, neste caso através do professor Gregório Varvakis. Em seguida, discorreu sobre as temáticas abordadas e a programação do seminário.

Os trabalhos apresentados representam resultados parciais ou finais de pesquisas de tese de doutorado, dissertação de mestrado ou iniciação científica dos integrantes do Grupo. Deste ponto em diante, serão descritos os trabalhos apresentados, sob a seguinte estrutura: título, palestrante, endereço eletrônico e titulação, abordagem e perguntas e/ou comentários da plateia, sendo que ao final de cada dia do evento foi realizada discussão, tópico que também apresentaremos, mantendo a ordem de apresentação conforme o dia em que ocorreu.

\subsection{Apresentações do primeiro dia (06/12/2010)}

O primeiro dia do seminário (06/12/2010) foi dedicado à linha de pesquisa Informação, comunicação, educação e sociedade, contando com a participação de palestrantes convidados , alunospesquisadores do Programa de Pós-Graduação em Ciência da Informação.

\section{1) Pesquisa escolar na educação básica: discurso de bibliotecários catarinenses}

Eliane Fioravante Garcez (efgarcez@ig.com.br) - bibliotecária escolar, especialista em Gestão da Informação (UFSC) e em Gestão de Bibliotecas (UDESC), mestre em Ciência da Informação (PGCIN/UFSC) com orientação do professor Dr. Francisco das Chagas de Souza.

Discorre sobre sua Dissertação de Mestrado, versando sobre a representação social de grupo de bibliotecários atuantes na área escolar de Santa Catarina.

A investigação realizada enquadra-se no campo qualitativo e no das representações sociais. O foco são as representações da pesquisa escolar expressas pelos profissionais de Biblioteconomia que integram o Grupo de Bibliotecários da Área Escolar de Santa Catarina (GBAE/SC). O objetivo central do estudo 
foi conhecer as representações que o bibliotecário constrói acerca da atividade de pesquisa no contexto da escola de Educação Básica. O referencial teórico pauta-se na Teoria Processualista (TP) de Norbert Elias e na Teoria da Construção Social (TCS) de Peter Berger e Thomas Luckmann. Metodologicamente, o estudo foi desenvolvido com referenciais da Teoria das Representações Sociais (TRS) de Serge Moscovici. Como instrumental metodológico foram utilizados um roteiro de entrevista composto de 7 questões abertas para recolher as opiniões dos locutores e um questionário para obtenção de características das instituições e dos entrevistados. Para análise e interpretação dos discursos coletados foi adotada a técnica do Discurso do Sujeito Coletivo (DSC), de Ana Maria Cavalcanti Lefèvre e Fernando Lefèvre. Além das representações sobre pesquisa escolar extraídas do discurso desse coletivo, o estudo sinalizou que o bibliotecário tem encontrado dificuldade para lidar com a pesquisa na escola. Percebe-se que a inclusão da biblioteca no planejamento do professor, ainda é pouca. No entanto, a inserção do bibliotecário nesse contexto educativo e a interação dele com os demais sujeitos escolares mostram-se como um dos caminhos para a construção de outra realidade; nela o professor ensinará utilizando-se da biblioteca da escola e o bibliotecário terá melhor compreensão sobre as questões pedagógicas.

\section{2) Ética e deontologia profissional nos anais do Congresso Brasileiro de Biblioteconomia, Documentação e Ciência da Informação de 1991 a 2007}

Katiusa Stumpf (belabruxinha.13@gmail.com) - bacharel em Biblioteconomia (UFSC) e mestranda em Ciência da Informação (PGCIN/UFSC), sob orientação do professor Dr. Francisco das Chagas de Souza.

Apresentou os resultados de pesquisa realizada através do Programa Institucional de Bolsas de Iniciação Científica (PIBIC/CNPq), desenvolvida no período de 2008-2009 sob orientação do professor Dr. Francisco das Chagas de Souza.

Trata da ética como um tema de interesse do Congresso Brasileiro de Biblioteconomia e Documentação (CBBD), focando-se a produção consolidada nos anais de sete edições $\left(16^{\mathrm{a}}\right.$ a $\left.22^{\mathrm{a}}\right)$ deste evento, que ocorreram nos anos de 1991, 1994, 1997, 2000, 2002, 2005 e 2007. Metodologicamente, o trabalho envolveu: 1) a pesquisa do tipo bibliográfico (quanto ao material utilizado para a obtenção dos conteúdos que permitissem a formação do embasamento teórico, visando sustentar a interpretação dos resultados; 2) a pesquisa de tipo documental (quanto à utilização dos anais e dos relatórios gerais dos eventos do CBBD para a coleta dos dados primários necessários ao alcance dos objetivos) e 3) a pesquisa de tipo exploratório (quanto aos objetivos pretendidos). Objetivou-se conhecer os seguintes 
fatores: a) sobre o que tratavam os trabalhos apresentados nas edições do CBBD realizadas de 1991 a 2007, que abordavam o tema: Ética; b) que abertura temática existia para tratar o assunto correspondente aos termos Ética, Moral e Deontologia profissional; c) quais foram as sequências de tratamento temático propostas para essas edições dos eventos; d) quais foram as recomendações aprovadas ao final de cada edição e incorporadas aos relatórios gerais, inclusive, sobre o que era mencionado quanto aos aspectos relativos a temática deste estudo. Assim, foram localizados quatro trabalhos tratando da temática em questão, unicamente em duas edições do evento. Nas outras cinco edições do Congresso não foram apresentados quaisquer trabalhos sobre ética. A maioria destas edições do CBBD não deu clara abertura temática para que a ética pudesse ser tratada. Quanto à sequência temática proposta na grade de programação das edições do evento, nota-se que as questões voltadas para o caráter social da profissão, inclusive no que diz respeito a ética profissional, sempre são deixadas para o final da listagem de subtemas. Na maioria das vezes nenhuma recomendação final dos relatórios gerais manifestou maiores interesses nos temas pouco explorados. Conclui-se que as profissões, para permanecerem aceitas pela sociedade, precisam reestruturar-se simultaneamente às modificações do ambiente que as assimila e transformar os conteúdos daí produzidos em matéria para a formação dos membros dessas profissões. Daí a importância de eventos como o CBBD para a Biblioteconomia; pois é através destes eventos que os profissionais podem se organizar para manter a profissão dinâmica. A ética, entretanto, é um tema pouco explorado e apesar de existir preocupação com o assunto por parte de alguns profissionais, ainda é ignorado pela maioria dos bibliotecários, pois o que falta, às vezes, como demonstraram os resultados deste estudo, é participação, cooperação e união de tais profissionais.

Ao final da apresentação, a palestrante foi questionada sobre quais outras medidas poderiam ser adotadas, tendo como cenário o resultado de sua pesquisa, ao que a mesma respondeu sugerindo mais pesquisa sobre a temática para que possa haver uma maior discussão sobre o tema. A palestrante foi questionada, também, sobre como fica a questão dos documentos na era digital, visto que houve dificuldade na recuperação dos anais do congresso como fonte da pesquisa, ao que a mesma respondeu que esse pode ser um tema para uma nova pesquisa na área.

\section{3) Bibliotecas comunitárias: espaços de interação social e desenvolvimento pessoal}

Rosangela Madella (ro_madella@yahoo.com.br) - bacharel em Biblioteconomia (UDESC) e mestre em Ciência da Informação (UFSC), orientada pelo professor Dr. Francisco das Chagas de Souza. 
Em sua apresentação, discorreu sobre a pesquisa de mestrado "Bibliotecas comunitárias: espaços de interação social e desenvolvimento pessoal”, defendida em 2010.

A palestrante inicia sua apresentação contextualizando sua formação em nível de escola primária na cidade de Galvão, oeste catarinense, e o caminho percorrido até chegar ao mestrado, justificando sua escolha pessoal e seu interesse pelo tema pesquisado, gestão de bibliotecas comunitárias.

No referido trabalho, foram analisadas as manifestações de agentes atuantes em quatro bibliotecas comunitárias sediadas em Florianópolis: Biblioteca Barca dos Livros, situada na Lagoa da Conceição; Biblioteca Livre do Campeche (BILICA), localizada no Campeche; a Biblioteca Comunitária da Fundação Vidal Ramos, do centro da cidade e a Biblioteca Comunitária da Barra da Lagoa, com sede na Barra da Lagoa. Foi empregada na pesquisa a metodologia do tipo qualitativa, tendo como fundamentação teórica e metodológica a sociologia do conhecimento e a teoria das representações sociais e coletivas. A técnica de análise para a tabulação dos discursos, coletados por meio de entrevistas e questionários, foi o Discurso do Sujeito Coletivo (DSC) construída por Lefèvre e Lefèvre. $\mathrm{Na}$ análise, foi identificada a menção da falta de políticas públicas de incentivo por parte do Estado, sendo a biblioteca um ambiente de construção da cidadania e também um espaço de muitas doações de livros para as bibliotecas comunitárias. Em relação aos públicos que frequentam e os públicos a ser atingidos pelo trabalho da biblioteca comunitária, é possível visualizar a comunidade do entorno, desde as crianças, adolescentes, adultos até os idosos. Um público heterogêneo, do pescador ao professor universitário. No que concerne às manifestações discursivas sobre a identificação das contribuições da biblioteca comunitária, destaca-se o desenvolvimento das habilidades de leitura do público, a possibilidade de maior acesso ao conhecimento e a participação nos eventos que acontecem na biblioteca, pois a mesma integra e permite uma formação ao ato de ler. Evidenciou-se que a biblioteca sendo localizada próximo de sua casa, facilita e aproxima o indivíduo dos livros.

Com os resultados, apresentou uma abordagem sobre as representações sociais que os diversos agentes envolvidos na organização e gestão de bibliotecas comunitárias constroem sobre a participação destas no funcionamento da sociedade, a partir do pensamento dos que nelas atuam.

Ao final da apresentação foram realizados alguns questionamentos pelos participantes, conforme segue:

- Questionamento 1: A metodologia utilizada na sua pesquisa propicia convivência face-a-face com os pesquisados. Gostaria de saber se esse contato permitiu você ver "Galvão" no momento da pesquisa? 
Resposta da palestrante: Sim, Galvão e Florianópolis não são tão diferentes, pois no bairro não se tem acesso com facilidade a biblioteca, a interface não existe - foi evidente - os computadores podem existir, mas pode-se ter e não saber usar. Falta o suporte humano.

- Questionamento 2: Essa falha pode ser a falta da presença de um profissional?

Resposta da palestrante: O responsável precisa ser mais humano, além de profissional.

- Questionamento 3: Você concorda que a biblioteca comunitária vai mudar sua função, o objetivo da biblioteca pública?

Resposta da palestrante: Por exemplo, Galvão tem uma biblioteca, tem profissional (sobrando), deveria entrar em cena uma pessoa com ação, vontade para fazer a diferença. É preciso uma necessidade de atuação independente do diploma, necessário "minha diferença" como profissional.

- Questionamento 4: Tendo biblioteca e livro, como fica a biblioteca comunitária?

Resposta da palestrante: A biblioteca comunitária faz o que a biblioteca publica não faz. Pode ser um trabalho em conjunto e isso seria melhor para a comunidade.

\section{4) Discussão final}

Elizete Vieira Vitorino (elizete@cin.ufsc.br) - mestre em Engenharia de Produção (UFSC), doutora em Engenharia de Produção (UFSC), professora do Departamento de Ciência da Informação (CIN/UFSC), Professora Pesquisadora do Programa de Pós-Graduação em Ciência da Informação (PGCIN/UFSC).

A professora Elizete Vieira Vitorino fez uma síntese dos trabalhos apresentados na primeira noite do seminário e destacou as fundamentações teórico-metodológicas do grupo e a "contextualização" presente em todos os trabalhos. Falou sobre a importância da biblioteca no contexto escolar e na educação básica, bem como a presença do bibliotecário nesse ambiente.

Adverte para o fato de a pesquisa bibliográfica exploratória não ter muito reconhecimento e afirma que a mesma não trata somente de resultados, ela possui uma fundamentação teórica. Ao tratar da Teoria das Representações Sociais, parabenizou os avanços observados nas pesquisas dos estudantes de Mestrado que têm empregado a teoria e lembrou a necessidade em se avançar ainda mais ao que tange às ancoragens, uma parte da teoria que não tem sido muito explorada nos trabalhos do Grupo. 
Finalizou enfatizando que, certamente, fazer uma reflexão das três apresentações e seus propósitos é chamar atenção para que o Grupo se fortaleça e cresça. Com isso, agregar mais alunos da graduação, não somente de iniciação científica, mas também para grupos de discussão. Sugeriu a formação de grupos de discussão de literatura, com o propósito de discutir teorias, autores, metodologias e fortalecer o aprofundamento teórico e metodológico, sendo que estes grupos poderiam ser formados por níveis (graduandos, mestrandos, doutorandos) ou de forma mista. Destaca, também, a necessidade de divulgação das temáticas de pesquisa que o grupo estuda e a importância de resgatar as proposições de espaços futuros, verificando o que foi indicado nas dissertações para estudos futuros e dar continuidade nas pesquisas para fortificar as temáticas.

A palavra foi passada ao professor líder de pesquisa, professor Gregório Varvakis, que agradeceu a organização do evento e a participação da platéia, convidando-os a participar no dia seguinte como forma de conhecer o "outro lado da moeda", a questão da tecnologia, da inovação em serviços, o estudo de fluxo de informação e conhecimento.

\subsection{Apresentações do segundo dia (07/12/2010)}

O segundo dia do seminário (07/12/2010) foi dedicado à linha de pesquisa Gestão da Informação, qualidade e tecnologia, a qual contou com a participação de palestrantes convidados, alunos/pesquisadores do Programa de Pós-Graduação em Ciência da Informação e do Programa de Pós-Graduação em Engenharia Gestão do Conhecimento. Este dia foi conduzido pelo líder de pesquisa, professor Gregório Varvakis, que também conduziu a discussão ao final das apresentações.

\section{1) Periódico científico digital: interoperabilidade e inferência}

Gleisy Regina Bóries Fachin (gleisy@cin.ufsc.br) - mestre em Engenharia de Produção (UFSC), Professora do Departamento de Ciência da Informação (CIN/UFSC), doutoranda em Engenharia e Gestão do Conhecimento (UFSC), orientada pelo professor Gregório Varvakis.

Iniciou sua apresentação abordando o fato de as tecnologias de informação e comunicação (TIC) serem evolutivas por sua própria natureza. A cada dia surgem novas ferramentas, metodologias, aplicações e cabe a cada um manter a sua atualização, em dominar esses conhecimentos em sua área de atuação e, mais do que nunca, ter uma visão do todo que ocorre a sua volta.

$\mathrm{Na}$ era da informação e do conhecimento, com a Internet representando um imenso repositório de dados e informações e, diga-se de passagem, com muito lixo também, pesquisadores e cientistas 
deparam-se com um emaranhado de contextos, recursos, mecanismos e fórmulas para recuperar suas informações que, muitas vezes, se questionam em qual usar ou como usar. Cada área do conhecimento investe em recursos informacionais que atendem às necessidades de seus usuários, como: bases de dados, bibliotecas digitais, repositórios, portais e sítios específicos. Especial atenção é demandada para as informações científicas publicadas em periódicos científicos, considerados propulsores da evolução humana.

A Web proporciona uma amplitude de publicações nos mais variados formatos, padrões, tamanhos e idiomas. A propagação de recursos tecnológicos conduz a forma variada de publicação, armazenamento e disseminação de informações científicas, fundamentais para todas as áreas e todas as ciências. Desse modo, na visão de Gruszynski (2008) inúmeras são as iniciativas, projetos e ações para racionalizar os processos, como: busca, tratamento, disseminação, consulta e o ato de navegar de um sítio a outro, num emaranhado de ligações referenciais, sem contar com a recuperação relevante e eficaz, as quais são fundamentais para evitar a sobrecarga de conteúdos/informações aos usuários.

Defendido por vários autores, a credibilidade e visibilidade são aspectos inerentes e relevantes aos periódicos científicos (LE COADIC, 2004; MUELLER, 2006), bem como a necessidade de avaliação dos mesmos, quanto aos indicadores de impacto, de atualidade e de suas características físicas e interoperáveis (CAPLAN, 2000; GONÇALVES; RAMOS; CASTRO, 2006; LARIVIÈRE; GINGRAS, 2010) e, para atender todas as necessidades, os esforços voltam-se aos metadados.

Numa visão global, os metadados objetivam a recuperação da informação, ou seja, tornar possível e concreto o encontro entre uma pergunta formulada, a informação armazenada e o retorno positivo ao usuário solicitante. Conforme já discutia Robredo (1982, p. 3) “os estudos que podem servir de base à construção de instrumentos de controle terminológico, quer de forma manual ou digital". E isso é largamente discutido por Caplan e Arms, já em 1999, por Zeng e Qin (2008) e Zeng (2010). Nesse sentido, em cada época, a história é representada de alguma forma, possuindo características próprias, tanto de criação como de recuperação e de conservação das informações, em especial as científicas.

Essa pesquisa busca a identificação de metadados voltados para a informação científica, buscando formar um conjunto específico para periódico digital - que é e foi considerado como veículo propulsor no desenvolvimento da humanidade. Esse conjunto de metadados visa padronizar e promover a interoperabilidade e inferência dos periódicos científicos diante da atual teia de sistemas de recuperação que formam a Web.

Apresenta a problemática, aspectos metodológicos versus o universo a ser pesquisado, o direcionamento e alguns resultados. Questiona, da mesma forma, a dificuldade tecnológica, ou seja, a 
gama de recursos e sistemas existentes e disponíveis para a organização e tratamento de informações encontradas na Web, além do número expressivo de aplicações e indicações de soluções que "resolvem todos os problemas", mas que ao findar as análises, percebe que tratam de recursos direcionados a situações específicas, nas variadas áreas das ciências, onde cada um, cada área, procura resolver seus próprios problemas.

Finaliza, frisando que a adoção de metadados facilita, viabiliza e integra periódicos científicos e, que essa compilação pode ser adotada por todas as áreas do conhecimento.

\section{2) A inovação em serviços e o processo de criação do conhecimento}

Mauricio Cordeiro Manhães (manhaes@msn.com) - mestre em Engenharia e Gestão do Conhecimento (UFSC), orientado pelo professor Gregório Varvakis, cuja dissertação de mestrado recebeu o título de "A inovação em serviço e o processo de criação do conhecimento: uma proposta de método para design de serviço", a qual subsidiou parte dos resultados apresentados no Seminário.

Em sua apresentação, discorreu sobre a forma pela qual as organizações podem criar conhecimento a partir de redes de valor para a geração de novas proposições de serviço.

Dado o cenário competitivo global contemporâneo, a inovação em serviços é um tema que demanda ser estudado em maior abrangência e aprofundamento. No sentido de colaborar para o aumento do número dessas pesquisas é que foi proposto este trabalho. Embora exista uma diáspora de pesquisas sobre inovação e design, sobre conhecimento e colaboração, proporcionalmente são poucas as que procuram articular esses conceitos sob o signo do serviço e propor um artefato como resultado. Para a referida investigação, este estudo adotou o método de pesquisa da ciência-design ou DSRM (Design Science Research Method). Através de uma revisão de literatura de abrangência interdisciplinar, cobrindo os termos Inovação, Serviço, Design, Conhecimento e Gestão, foi possível articular e apresentar uma base de conhecimento integrado. Esta serviu de fundamento para a proposição de um método para a coleta de informações qualitativas e geração de conhecimento com a participação de uma rede de valor determinada. Estes são considerados insumos para a proposição de novos conceitos e valores, que ocorre no início do processo de desenvolvimento de novos serviços. O método proposto busca articular, entre outros, os conceitos de co-evolução entre os espaços problema e solução, o processo de criação do conhecimento e o de comunicação multimodal. Ele foi aplicado e demonstrou, de forma pragmática, a sua validade. Este trabalho, por fim, colaborou para preencher a lacuna identificada ao articular um conjunto de literatura interdisciplinar, ao propor um artefato na forma de um método e ao criar oportunidades para futuras pesquisas sobre o cenário exposto. 
Ao final da apresentação, o palestrante foi questionado se há semelhança entre esse processo de metodologia pra avaliar grupo focal com páginas de web, ao que o mesmo respondeu que a discussão se pauta em como utilizar essa ferramenta a partir da socialização do conhecimento. O participante não é um rato ele esta definindo o serviço, como autor. O paralelo com web pode ser feito pelo fato de que essa ferramenta nasceu no entendimento de TI, mas há a necessidade do fator humano.

\section{3) Fluxo informacional no processo de produção de material didático para o curso de EaD}

Jacqueline Alexandre Martins (19jacqueline@gmail.com) - mestranda em Ciência da Informação (PGCIN/UFSC), sob orientação do professor Gregório Varvakis.

Expôs o andamento de sua pesquisa de mestrado, sob a abordagem do fluxo informacional e a produção de material didático. Salientou que a produção de material didático é uma das etapas mais importantes para o sucesso de cursos na modalidade à distância. A equipe de produção é caracterizada por uma equipe multidisciplinar na qual cada um assume de maneira diferenciada a tarefa e o desafio de trabalhar no texto produzido. As trocas de informações entre atores são essenciais no processo. Diante dessa realidade, a pesquisa tem por objetivo analisar o fluxo de informação no processo de produção de material didático impresso para cursos de educação à distância. Primeiramente foi necessário mapear o processo de produção de material didático identificando os atores do processo e os tipos de informações de entrada e saída de cada etapa. A pesquisa de campo foi realizada em três locais, o Senai - Serviço Nacional de Aprendizagem Industrial; e dois laboratórios localizados na própria Universidade Federal de Santa Catarina, CAD - Departamento de Ciências da Administração e na NECONT - Núcleo de Produção de Material EaD da Economia e Ciências Contábeis. A estratégia de verificação considera uma pesquisa do tipo exploratória e descritiva, com abordagem de análise qualitativa dos dados coletados por meio de entrevistas e questionários semiestruturados com os principais atores do processo: professor conteudista, designer instrucional, designer gráfico. Para a construção do questionário foram considerados quatro critérios: pontualidade, transparência, nível de detalhamento e o canal utilizado para transferência de informação. As análises basearam-se na influência desses quatro critérios na dinâmica do fluxo de informação, identificando as barreiras e facilitadores nesse fluxo. Como se trata de uma pesquisa em andamento as premissas apontam como barreiras e facilitadores do fluxo de informação: experiência do profissional com educação a distância; falta, excesso ou suprimento de informação; padronização; importante o contato pessoal para esclarecimento; questões pessoais de interpretação; organização da informação para uso entre outras. 


\section{5) Fluxo de conhecimento organizacional: uma abordagem a partir de uma revisão de literatura}

Diego Jacob Kurtz (diegokurtz@gmail.com) - mestrando em Engenharia e Gestão do Conhecimento (UFSC), sob orientação do professor Gregório Varvakis.

Em sua apresentação, discorreu sobre a criação e/ou aquisição de conhecimentos pelas organizações, a qual não significa algo fácil, sendo que a sua disseminação entre indivíduos, organizações e redes é ainda mais complexa. A compreensão de como ocorre o fluxo entre organizações pode auxiliar na melhoria, solução e/ou minimização de problemas associados aos processos nas cadeias produtivas onde estão inseridas as organizações. A apresentação objetivou, ainda, demonstrar a relevância do tema através de uma busca sistemática da literatura a partir do levantamento da base de dados Scopus. A fim de compreender quais são os enfoques dos estudos sobre fluxos de conhecimento foram identificados os vinte trabalhos mais relevantes a partir do número de citações da base. Trata da identificação de um gap de pesquisa e aplicação de um modelo proposto por Zhuge (2002), o qual foi abordado, no sentido de discutir a identificação e o mapeamento de fluxos de conhecimento dentro e entre organizações e o mapeamento do fluxo de conhecimento para melhoria de processos; como a aprendizagem organizacional em subunidades afeta os fluxos de conhecimento para outras subunidades; e a importância de se olhar o fluxo de conhecimento em uma rede por meio de rotinas interorganizacionais, visando à criação de vantagem competitiva.

Finalizou, salientando que o trabalho contribui tanto para a percepção da importância de se identificar e mapear fluxos de conhecimento quanto para a realização de futuras pesquisas empíricas que analisem fluxos de conhecimento dentro e entre organizações.

\section{4) Discussão final}

Gregório Jean Varvakis Rados (grego@deps.ufsc.br) - mestre em Engenharia de Produção (UFSC), doutor em Manufacturing Engineering (Loughborough University of Technology) (1991), professor do Departamento de Engenharia e Gestão do Conhecimento (EGC/UFSC) e do Programa de PósGraduação em Ciência da Informação (PGCIN/UFSC).

Ressalta a importância dos temas tratados no segundo dia do seminário sob a abordagem da linha Gestão da Informação, qualidade e tecnologia, do grupo GRITS, bem como a necessidade de haver uma interação entre as várias linhas de pesquisa que tratam de assuntos relacionados. 


\subsection{Apresentações do terceiro dia (13/12/2010)}

O terceiro dia do seminário $(13 / 12 / 2010)$ retomou a discussão dos temas em destaque na linha de pesquisa Informação, comunicação, educação e sociedade. A professora Gleisy Regina Bóries Fachin conduziu as apresentações, a discussão final e encerramento.

\section{1) Competência informacional e recursos informacionais na prática docente: discurso de professores da educação básica municipal à luz da Ciência da Informação}

Rafaela Paula Freitas (rafaelapfreitas@univali.br) - mestre em Ciência da Informação (PGCIN/UFSC), orientada pelo professor Dr. Francisco das Chagas de Souza.

Discorreu sobre os resultados de sua Dissertação de Mestrado sobre competência informacional no ambiente escolar, defendida em 2010. Iniciou salientando que o termo competência Informacional e recursos informacionais no ambiente escolar são os destaques desta pesquisa. Baseada nos discursos dos professores são relacionadas suas práticas, seus conhecimentos, suas atitudes e suas habilidades no que se refere à utilização dos recursos informacionais disponíveis na escola, assim como a relação que os professores têm com tais recursos. A metodologia utilizada e o uso da técnica do Discurso do sujeito coletivo possibilitou um olhar diferenciado, tanto para a pesquisadora quanto para os professores participantes da pesquisa no conhecimento e na utilização dos atributos da competência informacional.

\section{2) Ética profissional do bibliotecário atuante no segmento empresarial de Santa Catarina}

Daniella Camara Pizarro (daniellapizarro@hotmail.com) - mestre em Ciência da Informação (PGCIN/UFSC), orientada pelo professor Dr. Francisco das Chagas de Souza.

Expôs os resultados de sua Dissertação de Mestrado defendida em 2010. Ao iniciar o discurso, sinalizou satisfatoriamente que o trabalho foi premiado no XI ENANCIB, realizado neste ano.

Pôs em evidência que o objetivo geral do estudo consistiu em compreender as representações de ética profissional apreendidas nos discursos dos bibliotecários atuantes em empresas de Santa Catarina. Na fundamentação conceitual, aprofundaram-se os conceitos de ética e suas abordagens contemporâneas, a deontologia e ética bibliotecária, o ambiente empresarial e seus desafios éticos. Já a fundamentação teórico-metodológica concentrou-se nos preceitos da sociologia do conhecimento, do construtivismo social, e na teoria das representações sociais. A pesquisa teve abordagem qualitativa, a coleta de dados 
realizou-se através de um roteiro de entrevista semiestruturado, e a análise dos dados apoiou-se na técnica do Discurso do Sujeito Coletivo (DSC). A partir dos discursos dos entrevistados foram detectados três pontos relevantes sobre esse coletivo: o desconhecimento da conceituação de ética e ética profissional, assim como, da sua importância e à falta de domínio significativo do conteúdo do Código de Ética Profissional do Bibliotecário Brasileiro. O conceito de ética expresso confunde-se com o conceito de moral e ainda, esse coletivo tem noções de ética relacionadas com alteridade, caráter e comportamento. Assim como a ética geral, há uma falta de entendimento sobre o conceito de ética profissional, reforçado pelo desconhecimento do conteúdo do Código de Ética do Bibliotecário Brasileiro. Merece atenção, também, a influência que os pressupostos éticos empresariais exercem na conduta ética do bibliotecário que atua nesse ambiente. Fica claro que não há espaço para questionamento dos valores da empresa, sendo que a conduta ética empresarial prevalece. A oferta e o repasse das informações são regulados de forma a obter competitividade e a lucratividade para as empresas. O referido estudo teve como pano de fundo o contexto da pós-modernidade, onde valores de uma racionalidade técnica e instrumental predominam no pensamento e no agir do homus economicus, propiciando um vazio ético e a falta de referências para nortear o agir humano.

\section{3) Impactos da atuação da ABEBD entre os anos 1967 e 2000 na inovação curricular}

Francisco das Chagas de Souza (chagas@cin.ufsc.br) - mestre em Ciência da Informação (UFMG), doutor em Educação (UNIMEP), Professor do Departamento de Ciência da Informação (CIN/UFSC)

Iniciou seu discurso informando à platéia que o trabalho foi originalmente apresentado no GT 6 da ANCIB "Informação, Educação e Trabalho", como parte das Comunicações Orais expostas por ocasião do XI Encontro Nacional de Pesquisa em Ciência da Informação - XI ENANCIB 2010, realizado de 25 a 28 de outubro de 2010, na cidade do Rio de Janeiro, RJ. Expõe e discute parte de estudo em que se buscou compreender o alcance das ações de política institucional e acadêmica da Associação Brasileira das Escolas de Biblioteconomia e Documentação (ABEBD).

No estudo, utilizou-se uma abordagem sócio-histórica, sustentada nas teorias: con(figuracional) e construcionista-interacionista. Metodologicamente, a pesquisa responde a uma abordagem qualitativa. Foram colhidos discursos de dirigentes da entidade, tratando-os e analisando-os com o emprego da técnica do Discurso do Sujeito Coletivo (DSC). Após a análise dos discursos obteve-se um discurso coletivo, que foi interpretado com vistas a chegar-se a um conhecimento das representações dos dirigentes sobre os impactos que a entidade proporcionou ao ambiente e contexto de realização do 
ensino de graduação em Biblioteconomia no Brasil. Percebeu-se, ao final, a ocorrência de impactos que contribuíram tanto positiva quanto negativamente para a configuração do currículo desta área.

\section{4) Competência informacional: o discurso dos profissionais da informação dirigentes de bibliotecas vinculadas a instituições de ensino superior (IES) - saberes em transformação}

Elizete Vieira Vitorino (elizete@cin.ufsc.br) - mestre em Engenharia de Produção (UFSC), doutora em Engenharia de Produção (UFSC), professora do Departamento de Ciência da Informação (CIN/UFSC), Professora Pesquisadora do Programa de Pós-Graduação em Ciência da Informação (PGCIN/UFSC).

A exposição realizada resulta de parte de uma vasta pesquisa sobre representações sociais acerca da competência informacional dos profissionais da informação com o objetivo de comunicar uma parcela dos achados da pesquisa Competência Informacional, nas dimensões técnica, estética, ética e política: o discurso dos dirigentes de bibliotecas vinculadas a Instituições de Ensino Superior (IES) - Saberes em Transformação e, em específico, contribuir para a elaboração de um corpus teórico sobre Competência Informacional, a partir do discurso dos Profissionais da Informação dirigentes de bibliotecas vinculadas a IES no solo catarinense, mas, sobretudo, no contexto brasileiro. As noções completas - o discurso coletivo - elaboradas a partir das substâncias individuais - discurso de cada Profissional da Informação, num total de (13) treze, revelou algumas fossilizações - representações sociais arraigadas -, mas também saberes em transformação que se revelam nesse patchwork complexo e vital: surge da análise desse discurso a recompensa de que a visão da utilidade ainda pregada na formação inicial e continuada dos profissionais da informação dê lugar à multidimensionalidade, um esforço para além da dimensão técnica e que consiste na inclusão da ação e da experiência concreta e das dimensões estética, ética e política na aprendizagem. O que se propõe, ao divulgar os principais resultados da pesquisa realizada, é considerar o desenvolvimento da Competência Informacional na formação inicial e contínua de Profissionais da Informação como um fenômeno o que, antes era visto apenas como um conceito. Estamos sugerindo que pessoas e grupos, longe de serem receptores passivos, pensam por si mesmos, produzem e comunicam incessantemente suas próprias representações e soluções às questões que eles mesmos colocam e são como alimento para o pensamento desses dirigentes e para a criação de teorizações para a realidade brasileira, necessária ao desenvolvimento da noção de Competência Informacional para esse cenário. 


\section{5) Discussão final e encerramento}

Gleisy Regina Bóries Fachin (gleisyrbf@gmail.com) - mestre em Engenharia de Produção (UFSC), Professora do Departamento de Ciência da Informação (CIN/UFSC), doutoranda em Engenharia e Gestão do Conhecimento (UFSC).

A professora Gleisy Fachin realizou uma síntese das apresentações, destacando os pontos principais levantados nas várias exposições e, principalmente, a articulação entre as pesquisas.

Após sua intervenção, os integrantes do Grupo passaram a deliberar sobre as próximas atividades. Nesse sentido, concordaram em um agendamento provisório para a realização da primeira reunião de 2011 do Grupo para 15 de março de 2011, com o propósito de dar continuidade aos encontros periódicos. Considerou-se a proposta de realização do seminário anualmente e em uma data mais favorável para a adesão de um maior número de participantes no evento, tendo em vista o acúmulo de atividades para professores e estudantes no final do ano. Salientou-se, ainda, a possibilidade de realização de um Seminário Bienal de TCC's, como articulações a serem pensadas pelo Grupo. Além disso, considerou-se estipular uma programação de metas a serem atingidas pelo GRITS.

Em suma, o evento condensou a eficácia das pesquisas em andamento e concluídas pelo grupo e evidenciou o desejo de sintonizar as linhas de pesquisa através da dinâmica de grupos, visando o seu fortalecimento através de atividades de aprofundamento teórico e metodológico, de eventos e articulações relevantes para o fortalecimento do Grupo. Chamou-se atenção para o desejo de ampliar as relações com outros grupos de pesquisa e pesquisadores, promovendo o intercâmbio entre membros do Grupo, bem como capturar propostas de projetos com a promoção dos eventos, momento em que há trocas de informação.

\section{CONCLUSÃO}

Como conclusão do seminário, destaca-se a importância da articulação entre as linhas de pesquisa e seus pesquisadores para o fortalecimento das discussões apresentadas e para a consolidação do grupo de pesquisa. Além disso, a disseminação da informação para os colegas, bem como para a comunidade, por si só, justifica a realização do evento. 
Observação: os palestrantes forneceram resumos, por escrito, de suas falas, como subsídio à elaboração deste texto final.

Originais recebidos em: 03/04/2011

Aceito para publicação em:03/052011 